CASE REPORT

\title{
Malignant glomus TUMOR OF THE FOOT With OBVIOUS NEUROENDOCRINE DIFFERENTIATION: A CASE REPORT WITH IMMUNOHISTOCHEMICAL STUDIES
}

TADASHi TERADA

Department of Pathology, Shizuoka City Shimizu Hospital, Shizuoka, Japan

\begin{abstract}
Obvious neuroendocrine differentiation has not been reported in glomus tumor. The author herein reports a malignant glomus tumor of the foot showing obvious neuroendocrine differentiation. A 63-year-old woman presented with tumor of the left foot. The tumor was superficially seated, and located in the dermis. It was completely resected with wide margins. It measured $0.7 \times 0.7 \times 0.6 \mathrm{~cm}$. Microscopically, the tumor was composed of atypical epithelioid cells located around blood vessel-like structures. The epithelioid cells showed relatively clear cytoplasm and severe cellular atypia, and resembled basal cell carcinoma. Focal areas of squamoid differentiation, carcinoid patterns, and neural differentiations were seen. There was no necrosis or atypical mitosis. However, mitotic figures were seen in 16 per 50 high-power-fields (HPF). The hematoxylin and eosin (HE) diagnosis was basosquamous carcinoma. Immunohistochemically, the tumor cells were strongly positive for vimentin, $\alpha$-smooth muscle actin, and neuron-specific enolase. The tumor was focally positive for NCAM, synaptophysin and chromogranin. The blood vessel-like structures had a layer of CD31- and CD34-positive endothelial cells. $\mathrm{Tp} 53$ was positive and the Ki-67 labeling index was $23 \%$. The tumor cells were negative for cytokeratin (CK) AE1/3, CK CAM5.2, CK5, CK6, CK7, CK8, CK14, CK18, CK19, CK20, p63, EMA, CEA, CA19-9, desmin, myoglobin, HMB-45, Melan-A, S100 protein, MUC1, MUC2, MUC5AC, and MUC6. Taken together with HE histology, the tumor was labeled as malignant glomus tumor with neuronal differentiation, based on the classification system of Folpe et al. The post-pathological diagnosis whole body examination using CT, MRI, PET, and endoscopies identified no tumors. The patient is now free from tumor and healthy 18 months after the resection.
\end{abstract}

Key words: glomus tumor, malignant, neuroendocrine, immunohistochemistry.

\section{Introduction}

The recent recognition of the concepts of perivascular myoid cell phenotype and perivascular epithelioid cell phenotype has changed the concept of angiogenic tumors, in particular "hemangiopericytoma"-like tumors $[1,2]$. The perivascular myoid cell concept has yielded the recognition of myoperi- cytoma [3-8], myofibroma [4], myofibromatosis [9], angioleiomyoma $[10]$, and glomus tumors (GTs) [9, $11,12]$, while the perivascular epithelioid cell concept that shows melanocytic lineage has led to the recognition of PEComa $[13,14]$, clear cell sugar tumor $[15,16]$, angiomyolipoma $[17]$, and lymphangiomyomatosis [1]. These tumors belong to a spectrum of perivascular myoid cell tumors and perivascular 
epithelioid cell tumors, and there are some overlaps among these entities.

Glomus tumor is a rare tumor that recapitulates the appearances of the perivascular myoid cells of the normal glomus body. Malignant GT (MGT) is very rare, and only a few cases have been reported [18$25]$. The malignancy of GT is now based on the system proposed by Folpe et al. in 2001 [12]. Obvious neuroendocrine features of GT have not been reported. The author herein reports on a case of MGT of the foot showing obvious neuroendocrine differentiation.

\section{Case report}

A 63-year-old woman consulted our hospital because of a small tumor of the left foot. The tumor was superficially situated, and located in the dermis. The tumor was completely resected with wide margins. The tumor measured $0.7 \times 0.7 \times 0.6 \mathrm{~cm}$.

Microscopically, the tumor was located in the dermis, and well defined from the surroundings with focal capsules. No lymphovascular permeation was seen. The surgical margins were negative; thus the tumor was completely resected. The tumor was composed of atypical epithelioid cells located around blood vessel-like structures (Figs. 1A and 1B). The epithelioid cells had relatively clear cytoplasm and had severe cellular atypia and resembled basal cell carcinoma (Figs. 1B and 1C). Focal areas of squamoid differentiation (Fig. 1D), carcinoid patterns (Fig. 1E), and neuroid differentiation (Fig. 1F) were seen. There were close associations between tumor cells and nervous tissues. There was no necrosis or atypical mitosis. However, mitotic figures were seen in 16 per 50 high power fields (HPF). The hematoxylin and eosin (HE) diagnosis was basosquamous carcinoma.

An immunohistochemical study was done using Dako-Envision methods, as previously reported [2631]. Immunohistochemically, the tumor cells were strongly positive for vimentin (Fig. 2A), $\alpha$-smooth muscle actin (ASMA) (Fig. 2B), and neuron-specific enolase (NSE) (Fig. 2C). The tumor was focally positive for NCAM (Fig. 2D), synaptophysin (Fig. 2E) and chromogranin (Fig. 2F). The blood vessel-like structures had a layer of CD31- and CD34-positive endothelial cells (Fig. 2G). The p53 was positive (Fig. $2 \mathrm{H})$ and the Ki-67 labeling index was $23 \%$.

The tumor cells were negative for cytokeratin (CK) AE1/3, CK CAM5.2, CK5, CK6, CK7, CK8, CK14, CK18, CK19, CK20, p63, EMA, CEA, CA19-9, desmin, myoglobin, HMB-45, Melan-A, S100 protein, MUC1, MUC2, MUC5AC, and MUC6. Taken together with HE histology, the tumor was labeled as malignant GT with neuronal differentiation, based on the classification system of Folpe et al. [12].

The post-pathological diagnosis whole body examination using computed tomography (CT), magnetic resonance imaging (MRI), positron emission tomography (PET) and endoscopies identified no tumors. The patient is now free from tumor and is healthy 18 months after the resection.

\section{Discussion}

The present tumor was superficially seated in the foot. The tumor was composed of epithelioid polygonal cells with severe cellular atypia. The tumor cells were located around the vascular structures. Immunohistochemically, the tumor cells were positive for vimentin and ASMA, and negative for S100 protein, Melan-A and HMB-45. These histological features are those of glomus tumor (GT) [9, 11, 12].

According to Folpe et al. [12], the GTs are classified into the following 4 categories: MGT, symplastic GT, GT of uncertain malignant potential, and glomangiomatosis. Malignant GT is characterized by tumors with a deep location and a size of more than $2 \mathrm{~cm}$, or atypical mitotic figures, or moderate to high nuclear grade and 5 or more mitotic figures per $50 \mathrm{HPF}$. Symplastic GT is characterized by tumors with high nuclear grade in the absence of any other malignant features. Glomus tumor of uncertain malignant potential is characterized by tumors that lack criteria of malignant GT or symplastic GT but have high mitotic activity and superficial location only, or large size only. Glomangiomatosis is characterized by tumors with histological features of diffuse angiomatosis and excess of glomus cells.

The present tumor is apparently MGT based on Folpe's criteria [12]. It showed marked nuclear atypia and many mitotic figures (16 per $50 \mathrm{HPF}$ ). It did not have necrosis, deep location, or a large size $>2 \mathrm{~cm}$. The p53 was strongly positive, suggesting mutations of the p53 gene and malignant nature of tumor. The Ki-67 labeling was very high (25\%), indicating high cell proliferation and suggesting the malignant potential of the tumor.

Although the present tumor fulfills the criteria of MGT according to Folpe [12], there seem to be opinions that the cellular atypia is not sufficient to diagnose MGT in the present case. The follow-up period (18 months) of the present case is relatively short. However, the author thinks that the present tumor is malignant because it fulfilled Folpe's criteria for MGT [12]. Certainly, the follow-up period (18 months) is relatively short, but it is quite likely that the tumor is completely removed by the surgery, which was proved by the pathological examinations showing completely negative surgical margins. Thus, it is probable that the present tumor is malignant. However, it is believed that individuals having tumors labeled as MGT can show benign characteristics. In any case, the patient needs strict follow-up because it was histologically diagnosed as malignant. 

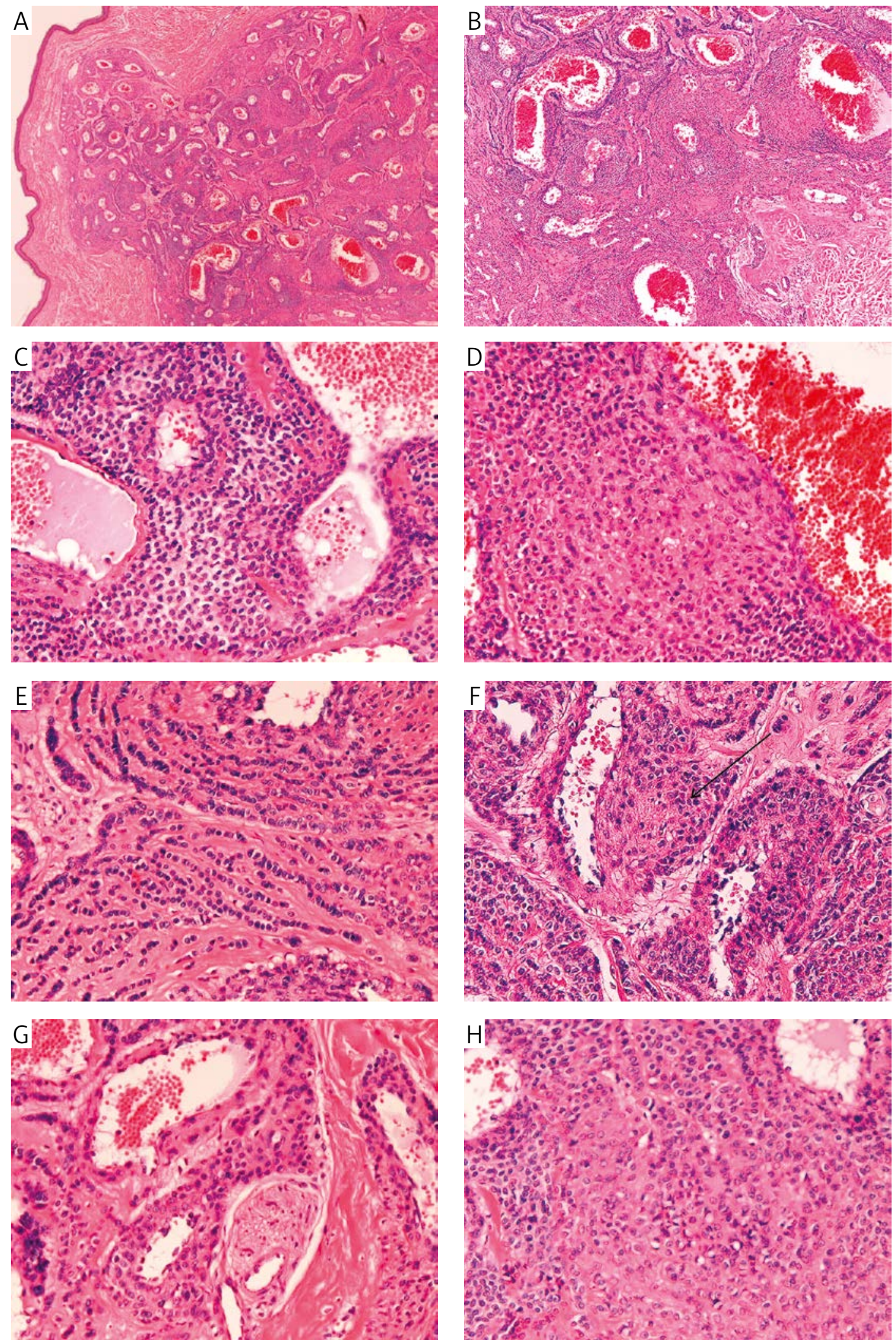

Fig. 1. Histology of the tumor. A) Very low power view of the tumor. The tumor is located in the dermis, and is well defined. No infiltrative growth is seen. The tumor shows proliferation of basaloid cells and shows features of basal cell carcinoma except for the angiomatoid structures. HE, magnification 20×. B) Medium sized magnification. The tumor shows basaloid cells and angiomatoid structures. HE, magnification $40 \times$. C) High power view. The tumor is composed of basaloid clear cells with angiomatoid features. HE, magnification $200 \times$. D) Focal areas show squamous cell differentiation. HE, magnification $200 \times$. E) Focal areas show carcinoid or rippenoid patterns consistent with basal cell carcinoma or neuroendocrine carcinoma. F) Very frequently, the tumor cells show neuroid differentiation (arrow). HE, magnification $200 \times$. G) Very frequently, there were close associations between tumor cells and relatively mature neuronal cells. HE, magnification $200 \times$. H) The tumor cells shows many mitotic figures. HE, magnification $200 \times$ 

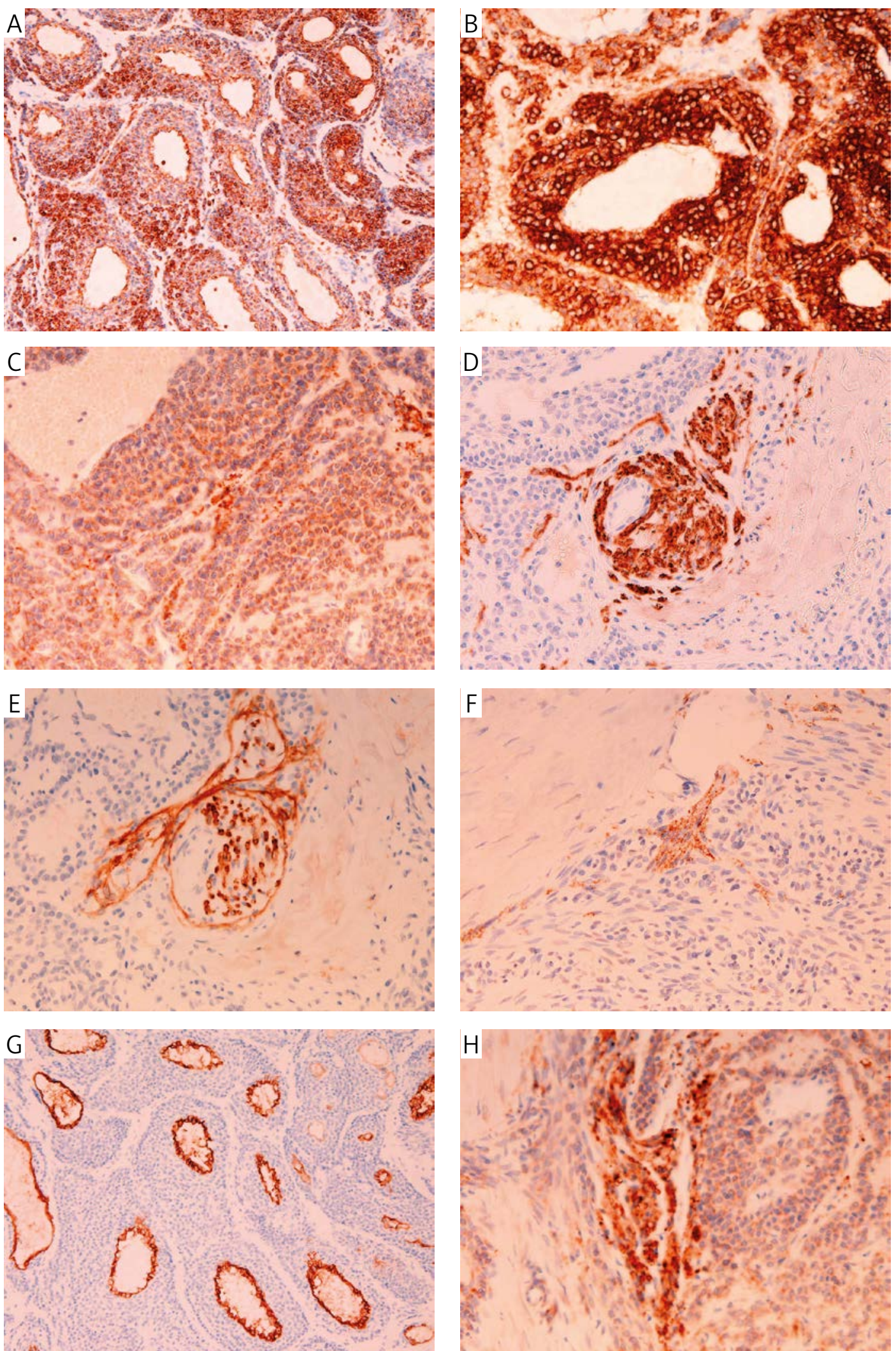

Fig. 2. Immunohistochemical features of the tumor. The tumor cells were strongly positive for $\alpha$-smooth muscle actin (A) and neuron-specific enolase (B). The tumor was focally positive for NCAM (C), synaptophysin (D) and chromogranin (E). The blood vessel-like structures had a layer of CD31- and CD34-positive endothelial cells (F). A-F: magnification 200×. The blood vessels-like structures had a layer of CD31- and CD34-positive endothelial cells $(\mathrm{G})$. The p53 was positive (H) and Ki-67 labeling index was $23 \%$. A-H: magnification $200 \times$ 
It is well known that MGT may show an aggressive clinical course $[18,19]$. The GT of the present patient did not show recurrence or metastasis 18 months after the resection. The patient is now being followed up carefully.

In the present study, the HE diagnosis was basosquamous carcinoma (BSC). The tumor first appeared on HE preparation as basal cell carcinoma (BCC). The tumor cells were basaloid, and epithelioid, and had significant atypia including mitotic figures. Squamoid differentiations were frequently seen, and there were carcinoid (rippenoid) patterns compatible with BCC. Such carcinoid and squamoid patterns appear to be extremely rare in MGT. The author's HE diagnosis was BSC, and the author was surprised by the immunohistochemical features indicating that the tumor cells showed no epithelial lineage but showed myopericytomatous characteristics. Thus, on HE preparations, the MGT should be differentiated from BCC and BSC. The author stresses that MGT may show histologies of BCC, carcinoid (rippenoid), squamous cell differentiation, and BSC on HE preparations. The basaloid nature, carcinoid (rippenoid) patterns and apparently squamous differentiation seen in the present MGT should be investigated further.

Differential diagnosis of GT includes other perivascular myoid cell tumors. Myopericytoma usually does not show epithelioid features of tumor cells, and shows nodularities of tumor cells [3-8]. Myopericytoma is positive for $\alpha$-smooth muscle actin [3-8]. However, the histological features of the present tumor are different from myopericytoma. The present tumor is different histologically from other perivascular myoid cell tumors, including myofibroma [4], myofibromatosis [9], and angioleiomyoma [10]. Myofibroma and myofibroblastoma show much more fibrotic areas, and the tumor cells are not polygonal. Angioleiomyoma (vascular leiomyoma) shows a combination of smooth muscles and vasculatures, and the tumor cells do not show epithelioid morphologies. The present case is not different from angiomatoid malignant fibrous histiocytoma (MFH) because of absence of storiform-pleomorphic and other patterns of angiomatoid $\mathrm{MFH}$.

The present tumor is different from perivascular epithelioid cell tumors, such as PEComa $[13,14]$. PEComa usually shows immunoreactivity of HMB45, Melan-A, and S100 protein [13, 14], and is histologically composed of clear cells with large hyperchromatic bizarre nuclei. The present tumor is histologically and immunohistochemically different from other perivascular epithelioid tumors including clear cell sugar tumor $[15,16]$, angiomyolipoma $[17]$, and lymphangiomyomatosis [1]. Clear cell sugar tumor mainly occurs in the lung and is composed of epithelioid clear cells. Angiomyolipoma shows a combina- tion of vasculatures, smooth muscles, and fat tissue. Lymphangiomyomatosis most commonly occurs in the lung. It is characterized by lymphatic-like spaces lined by myoid cells. These perivascular epithelioid tumors show immunoreactivity for $\mathrm{S} 100$ protein and melanosome proteins (HMB45 and Melan-A).

One of the most important and quite interesting findings in the present MGT is that the MGT has obvious neuroendocrine features. In the HE preparations, neuroid differentiations were frequently seen, and there were close associations between the tumor cells and relatively mature neurons. In addition, immunohistochemically, the tumor cells were diffusely and strongly positive for NSE. The tumor cells were also positive for NCAM, synaptophysin, and chromogranin. These immunohistochemical data support the HE histological observations that showed neuroid differentiation. Taken together with HE histology, it is concluded that the present MGT has neuroid or neuroendocrine features. Although many epithelial carcinomas may show focal neuroendocrine features, such an apparent phenomenon in GT has not been reported. Neuroendocrine differentiation is very rare in mesenchymal tumors.

There are several reports of focal neuroendocrine differentiation in GT, particularly gastric GT. Herein, most comprehensive investigations are mentioned. Wang et al. [32] reported that focal synaptophysin positivity was seen in 2/11 gastric GT, but no immunoreactivity for NCAM (0/11), NSE (0/11), or chromogranin (0/11). They also demonstrated ultrastructurally endocrine granules in some gastric GT. Miettinen et al. [33] found synaptophysin reactivity in 3/32 gastric GT. Kim et al. [34] observed ultrastructurally endocrine-type granules in one GT. Farrior et al. [35] noted endocrine activity of glomus jugulare tumors. Lawson et al. [36] found endocrine cells in the glomus jugular apparatus in carotid arteries. Of these comprehensive studies, the neuroendocrine features in GT of stomach and other sites are not prominent but only sparse. The ultrastructural endocrine granules also lacked conclusive findings of real endocrine granules. These GTs of stomach and other sites seem not to be authentic endocrine differentiation but only represent focal endocrine differentiation that is frequently seen in other neoplasms. In contrast, the GT of the present case shows obvious neuroendocrine features not considered as only neuroendocrine differentiation. Any way, comprehensive studies of neuroendocrine features in GT are mandatory in future. The author's previous work [37-52] showed that human embryonic and fetal smooth muscle cells and stem cells in the gastrointestinal tract show neuroendocrine antigens (NCAM, NSE, synaptophysin, and chromogranin), which are also markers of stem cells in developmental biology, in addition to KIT, PDGFRA, CD34, ErbB2, MET, 
and bcl-2. This finding supports the observation that a tumor with smooth muscle antigens also shows neuroendocrine phenotypes.

The implications of these neuroid or neuroendocrine features of the present MGT were unclear. Embryology shows that the glomus anlagen and neurons develop from the mesoderm. The association between the two is close in embryology. Thus, it is conceivable that GT may show neuroendocrine or neuroid differentiation. The carcinoid (rippenoid) patterns seen on HE preparations are never seen in conventional MGT, suggesting that the carcinoid pattern is a reflection of neuroendocrine differentiation. It is also possible that the present tumor is a kind of stem cell tumor, because NCAM, NSE, synaptophysin and chromogranin are antigens of stem cells of various types [37]. Other stem cell antigens including CD34 and CK14 were negative in the present study, but this negativity does not exclude stem cell cancer. This concept that GT is a stem cell tumor should be examined by the use of many stem cell antigens and molecular techniques.

In the present study, the tumor cells were negative for CK AE1/3, CK CAM5.2, CK5, CK6, CK7, CK8, CK14, CK18, CK19, CK20 and EMA, indicating that the present tumor is not an epithelial tumor. Tp63 was negative, showing that the present tumor is not squamous cell carcinoma, BCC, or myoepithelial carcinoma. CEA and CA19-9 were negative, suggesting that the present tumor is not adenocarcinoma. Desmin was negative. This negativity is difficult to explain, because GT may be positive for desmin. It is thought that some GTs may be negative for these intermediate filaments present in muscle cells. Myoglobin was negative, indicating that the present tumor shows no rhabdomyomatous differentiation. The meanings of HMB-45, Melan-A, and S100 protein are described in the text. MUC1, MUC2, MUC5AC and MUC6 were negative, indicating that GT does not have mucin core proteins (MUCs).

\section{The author declares no conflict of interest.}

\section{References}

1. Armah HB, Parwani AV. Perivascular epithelioid cell tumor. Arch Pathol Lab Med 2009; 133: 648-654.

2. Martignoni G, Pea M, Reghellin D, et al. PEComas: the past, the present and the future. Virchows Arch 2008; 452: 119132.

3. Mentzel T, Dei Tos AP, Sapi Z, Kutzner H. Myopericytoma of the skin and soft tissue: clinicopathologic and immunohistochemical study of 54 cases. Am J Surg Pathol 2006; 30: 104113.

4. Dray MS, McCarthy SW, Palmer AA, et al. Myoipericytoma: a unifying term for a spectrum of tumours that show overlapping features with myofibroma. A review of 14 cases. J Clin Pathol 2006; 59: 67-73.
5. Scott RS, Blank KL, Proffer LH, et al. Perivascular myoma of myopericytoma and myofibromatosis-type arising in a chronic scar. J Cutan Pathol 2006; 33: 231-235.

6. Laga AC, Tajirian AL, Islam MN, et al. Myopericytoma: report of two cases associated with trauma. J Cutan Pathol 2008; 35: 866-870.

7. McMenamin ME, Calonje E. Intravascular myopericytoma. J Cutan Pathol 2002; 29: 557-561.

8. Mikami Y, Shiomi T, Manabe T. Perivascular myoma: case report and immunohistochemical and ultrastructural studies. Pathol Int 2002; 52: 69-74.

9. Granter SR, Badizadegan K, Fletcher CD. Myofibromatosis in adults, glomangiopericytoma, and myopericytoma: a spectrum of tumors showing perivascular myoid differentiation. Am J Surg Pathol 1998; 22: 513-525.

10. Matsuyama A, Hisaoka M, Hashimoto H. Angioleiomyoma: a clinicopatholgic and immunohistochemical reappraisal with special reference to the correlation with myopericytoma. Hum Pathol 2007; 38: 645-651.

11. Miettinen M, Paal E, Lasota J, Sobin LH. Gastrointestinal glomus tumors: a clinicopathologic, immunohistochemical, and molecular genetic study of 32 cases. Am J Surg Pathol 2002; 26: 301-311.

12. Folpe AL, Fanburg-Smith JC, Miettinen M, Weiss SW. Atypical and malignant glomus tumors: analysis of 52 cases, with a proposal for the reclassification of glomus tumors. Am J Surg Pathol 2001; 25: 1-12.

13. Folpe AL, Mentzel T, Lehr HA, et al. Perivascular epithelioid cell neoplasms of soft tissue and gynecologic origin: a clinicopathologic study of 26 cases and review of the literature. Am J Surg Pathol 2005; 29: 1558-1575.

14. Liegl B, Hornick JL, Fletcher CD. Primary cutaneous PEComa: distinctive clear cell lesions of skin. Am J Surg Pathol 2008; 32: 608-614.

15. Lantuejoul S, Isaac S, Pinel N, et al. Clear cell tumor of the lung: an immunohistochemical and ultrastructural study supporting a pericytic differentiation. Mod Pathol 1997; 10: 1001-1008.

16. Pan CC, Yu IT, Yang AH, Chiang H. Clear cell myomelanocytic tumor of the urinary bladder. Am J Surg Pathol 2003; 27: 689-692

17. Tsui WM, Colombari R, Portmann BC, et al. Hepatic angiomyolipoma: a clinicopathologic study of 30 cases and delineation of unusual morphologic variants. Am J Surg Pathol 1999; 23: 34-48.

18. Brathwaite CD, Poppiti RJ Jr. Malignant glomus tumor: a case report of wide spreas metastases in a patient with multiple glomus body hamartomas. Am J Surg Pathol 1996; 20: 233-238.

19. Watanabe K, Sugino T, Saito A. Glomangiosarcoma of the hip: report of a highly aggressive tumour with wide spread distant metastases. Br J Dermatol 1998; 139: 1097-1101.

20. Skelton HG, Smith KJ. Infiltrative glomus tumor arising from a benign glomus tumor: a distinctive immunohistochemical pattern in the infiltrative component. Am J Dermatopathol 1999; 21: 562-566.

21. Kayal JD, Hampton RW, Sheehan DJ, Washington CV. Malignant glomus tumor: a case report and review of the literature. Dermatol Surg 2001; 27: 837-840.

22. Park JH, Oh SH, Yang MH, Kim NI. Glomangiosarcoma of the hand: a case report and review of the literature. J Dermatol 2003; 30: 827-833.

23. Khoury T, Balos L, McGrath B, et al. Malignant glomus tumor: a case report and review of literature, focusing on its clinicopathologic features and immunohistochemical profiles. Am J Dermatopathol 2005; 27: 428-432.

24. Cibull TL, Gleason BC, O'Malley DP, et al. Malignant cutaneous glomus tumor presenting as rapidly growing leg mass in a pregnant woman. J Cutan Pathol 2008; 35: 765-769. 
25. Terada T, Fujimoto J, Shirakashi Y, et al. Malignant glomus tumor of the palm: a case report. J Cutan Pathol 2011; 38: 381-384.

26. Terada T, Kawaguchi M, Furukawa K, et al. Minute mixed ductal-endocrine carcinoma of the pancreas with predominant intraductal growth. Pathol Int 2002; 52: 740-746.

27. Terada T, Kawaguchi M. Primary clear cell adenocarcinoma of the peritoneum. Tohoku J Exp Med 2005; 271: 271-275.

28. Terada T, Taniguchi M. Intraductal oncocytic papillary neoplasm of the liver. Pathol Int 2004; 54: 116-123.

29. Terada T, Takeuchi T, Taniguchi M. Hepatobiliary cystadenocarcinoma with cystadenoma elements of the gall bladder in an old man. Pathol Int 2003; 53: 790-795.

30. Terada T. Ductal adenoma of the breast: Immunohistochemistry of two cases. Pathol Int 2008; 58: 801-805.

31. Terada T. Gall bladder adenocarcinoma arising in Rokitansky-Schoff sinuses. Pathol Int 2008; 58: 806-809.

32. Wang ZB, Yuan J, Shi HY. Features of gastric glomus tumor: a clinicopathologic, immunohistochemical and molecular retrospective study. Int J Clin Exp Pathol 2014; 7: 1438-1448.

33. Miettinen M, Paal E, Lasota J, Sobin LH. Gastrointestinal glomus tumors: a clinicopathologic, immunohistochemical, and molecular genetic study of 32 cases. Am J Surg Pathol 2002; 26: 301-311.

34. Kim BH, Rosen Y, Suen KC. Endocrine-type granules in cells of glomus tumor of the stomach. Arch Pathol 1975; 99: 544547.

35. Farrior JB 3rd, Hyams VJ, Benke RH, Farrior JB. Carcinoid apudoma arising in a glomus jugulare tumor: review of endocrine activity in glomus jugulare tumors. Laryngoscope 1980; 90: 110-119.

36. Lawson W. The neuroendocrine nature of the glomus cells: an experimental, ultrastructural, and histochemical tissue culture study. Laryngoscope 1980; 90: 120-144.

37. Terada T. Smooth muscles and stem cells of embryonic guts express KIT, PDGFRRA, CD34 and many other stem cell antigens: suggestion that GIST arise from smooth muscles and gut stem cells. Int J Clin Exp Pathol 2013; 15: 1038-1045.

38. Terada T, Nakanuma Y. Development of human intrahepatic peribiliary glands: Histological, keratin immunohistochemical and mucus histochemical analyses. Lab Invest 1993; 68: 261269.

39. Terada T, Nakanuma Y. Profiles of expression of carbohydrate chain structures during human intrahepatic bile duct development and maturation: a lectin-histochemical and immunohistochemical study. Hepatology 1994; 20: 388-397.

40. Terada T, Kitamura Y, Nakanuma Y. Normal and abnormal development of the intrahepatic biliary system: A review. Tohoku J Exp Med 1997; 181: 19-32.

41. Terada T, Ashida K, Kitamura Y, et al. Expression of E-cadherin, alpha-catenin and beta-catenin during human intrahepatic bile duct development. J Hepatol 1998; 28: 263-269.

42. Terada T. Differentiation of intrahepatic peribiliary glands and pancreatic acinar cells from the remodeling ductal plate in human fetuses. Hepatology 2012; 56: 2004-2005.

43. Terada T, Nakanuma Y. Expression of pancreatic enzymes $(\alpha$-amylase, trypsinogen and lipase) during human liver development and maturation. Gastroenterology 1995; 108: 12361245.

44. Terada T, Nakanuma Y. Detection of apoptosis and expression of apoptosis-related proteins during human intrahepatic bile duct development. Am J Pathol 1995; 146: 67-74.

45. Terada T, Okada Y, Nakanuma Y. Expression of matrix proteinases during human intrahepatic bile duct development: A possible role in biliary cell migration. Am J Pathol 1995; 147: $1207-1213$.
46. Terada T, Nakanuma Y. Development of human peribiliary capillary plexus: A lectin-histochemical and immunohistochemical study. Hepatology 1993; 18: 529-536.

47. Terada T, Nakanuma Y. Expression of tenascin, type IV collagen and laminin during human intrahepatic bile duct development and in intrahepatic cholangiocarcinoma. Histopathology 1994; 25: 143-150

48. Terada T, Kato M, Horie S, Endo K, Kitamura Y. Expression of pancreatic alpha-amylase protein and messenger RNA on hilar primitive bile ducts and hepatocytes during human fetal liver organogenesis: an immunohistochemical and in situ hybridization study. Liver 1998; 18: 313-319.

49. Terada T, Ukita Y, Ueyama J, Ohta T. Protein expression of double-stranded RNA-activated protein kinase (PKR) in intrahepatic bile ducts in normal adult livers, fetal livers, primary biliary cirrhosis, hepatolithiasis and intrahepatic cholangiocarcinoma. Liver 2000; 20: 450-457.

50. Terada T, Ohta T, Nakanuma Y: Expression of transforming growth factor- $\alpha$ and its receptor during human liver development and maturation. Virchows Archiv 1994; 424: 669-675.

51. Terada T, Ashida K, K Endo K, et al. C-erbB-2 protein is expressed in hepatolithiasis and cholangiocarcinoma Histopathology 1998; 33: 325-331.

52. Terada T, Nakanuma Y, Sirica AE. Immunohistochemical demonstration of MET overexpression in human intrahepatic cholangiocarcinoma and in hepatolithiasis. Hum Pathol 1998; 29: $175-180$

\section{Address for correspondence}

Tadashi Terada

Department of Pathology

Shizuoka City Shimizu Hospital

Miyakami 1231 Shimizu-Ku

Shizuoka 424-8636, Japan

tel. 81-54-336-1111

fax 81-54-336-1315

e-mail: piyo0111jp@yahoo.co.jp 